\title{
DETEKSI DINI TERHADAP HIPERURISEMIA, HIPERKOLESTEROLEMIA DAN HIPERGLIKEMIA DI MASYARAKAT DESA KARIKIL RW O1 MANGKUBUMI KOTA TASIKMALAYA
}

\author{
Meri Meri ${ }^{1}$, Meti Kusmiati ${ }^{2}$,Tanendri Arrizqiyani ${ }^{3}$, Yane Liswanti ${ }^{4}$, Hendro Kasmanto ${ }^{5}$ \\ ${ }^{1,2,3,4,5)}$ Program Studi D3 Teknologi Laboratorium Medis, STIKes Bakti Tunas Husada Tasikmalaya \\ e-mail: metikusmiati@stikes-bth.ac.id
}

\begin{abstract}
Abstrak
Kesehatan individu dapat terdeteksi salah satunya melalui diagnosis laboratorium dengan menggunakan sampel darah. Kondisi hiperurisemia, hiperkolesterolemia dan hiperglikmemia berturut-turut merupakan keadaan meningkatnya kadar asam urat, kolesterol dan glukosa dalam darah. Kelebihannya dapat menimbulkan berbagai penyakit seperti gangguan fungsi ginjal, hipertensi, diabetes melitus, arterosklerosis, cardiovaskular dan lain-lain. Desa Karikil Kecamatan Mangkubumi Kota Tasikmalaya merupakan desa bnaan STIKes Bakti Tunas Husada Tasikmalaya yang memerlukan binaan dalam bidang kesehatan khususnya ke arah penyakit tidak menular (PTM).Sasaran kegiatan ini adalah warga RW 01 Desa Karikil Kecamatan Mangkubumi Kota Tasikmalaya. Luaran yang diharapkan adalah gambaran persentase warga yang mengalami hiperurisemia, hiperkolesterolemia dan hiperglikemia. Dengan demikian, mengingat pentingnya pencegahan terhadap penyakit tidak menular, pengabdian masyarakat ini bertujuan untuk mendeteksi dini terhadap hiperurisemia, hiperkolesterolemia dan hiperglikemia. Metode yang dilakukan adalah berupa penyuluhan dan pemeriksaan darah. Hasil yang diperoleh adalah 7,7\% mengalami hiperurisemia, dan 10\% mengalami hiperkolesterolemia, sedangkan 92,3\%, 90\% dan $100 \%$ secara berturut-turut memiliki kadar asam urat, kolesterol dan glukosa darah dalam keadaan normal.
\end{abstract}

Kata kunci: Deteksi dini, hiperurisemia, hiperkolesterolemai, hiperglikemia.

\begin{abstract}
One's health can be detected through laboratory diagnoses using blood samples. The conditions of hyperuricemia, hypercholesterolemia and hyperglycemia are successively increased levels of uric acid, cholesterol and blood glucose. The excess can cause various diseases such as kidney dysfunction, hypertension, diabetes mellitus, atherosclerosis, cardiovascular and others. Karikil Village, Mangkubumi Subdistrict, Tasikmalaya City is a target village of STIKes Bakti Tunas Husada Tasikmalaya which requires guidance in the health sector, especially towards noncommunicable diseases (PTM). The target of this activity is residents of RW 01 Karikil Village, Mangkubumi District, Tasikmalaya City. Expected output is a description of the percentage of people who have hyperuricemia, hypercholesterolemia and hyperglycemia. Thus, given the importance of prevention of non-communicable diseases, this community service aims to detect early on hyperuricemia, hypercholesterolemia and hyperglycemia. The method used is in the form of counseling and blood tests. The results obtained were 7.7\% having hyperuricemia, and $10 \%$ having hypercholesterolaemia, while $92.3 \%, 90 \%$ and $100 \%$ respectively had uric acid, cholesterol and blood glucose levels under normal conditions.
\end{abstract}

Keywords: Early detection, hyperuricemia, hypercholesterolemia, hyperglycemia.

\section{PENDAHULUAN}

Kondisi kesehatan individu akan terdeteksi salah satunya dengan melakukan pemeriksaan darah. Darah setiap individu yang normal diharapkan akan memberikan hasil pemeriksaan laboratorium dengan nilai normal. Beberapa penyakit seperti diabetes mellitus, gout, hipertensi, gangguan ginjal, dan gangguan fungsi hati serta gangguan fungsi jantung akan terdeteksi salah 
satunya adalah melalui diagnosis laboratorium, dengan melakukan pemeriksaan darah (Bishop, Fody, \& Schoeff, 2010).

Kadar asam urat yang meningkat dalam darah dapat menyebabkan gangguan kesehatan seperti penyakit serebrovaskular(Luo et al., 2016), gangguan fungsi ginjal (Ruilope \& Garciapuig, 2001), gout (Abbas, Lichtman, \& Pillai, 2016), penyakit kardiovaskular (Maiuolo, Oppedisano, Gratteri, Muscoli, \& Mollace, 2016) juga hipertensi (Ruilope \& Garcia-puig, 2001). Pada penelitian sebelumnya dapat menggambarkan bahwa hiperurisemia dapat menimbulkan gangguan kesehatan salah satunya gangguan fungsi ginjal. Fungsi ginjal tersebut dapat diperiksa dengan parameter cystatin-C sebagai parameter yang lebih akurat dibandingkan dengan parameter kreatinin darah. Pada hasil penelitian mengambarkan bahwa kadar cystatin-C yang meningkat dapat terjadi pada hiperurisemia. Hal tersebut menggambarkan bahwa adanya gangguan fungsi ginjal (Meri \& Liswanti, 2020).

Kadar kolesterol yang meningkatpun dapat menimbulkan gangguan kesehatan seperti gangguan pembuluh darah, dan gangguan fungsi jantung. Kristal kolesterol dapat menimbulkan inflamasi seperti arterosklerosis melalui jalur inflamasome. Beberapa sitokin proinflamasi akan dikeluarkan sehingga menimbulkan respon imun (Abbas et al., 2016)

Kadar gula dalam darah yang meningkat dapat menyebabkan gangguan kesehatan seperti adanya penyakit diabetes mellitus, glaukoma, gangguan fungsi ginjal, hipertensi dan komplikasi penyakit lainnya. Pada pandemi saat ini yaitu adanya COVID-19, dapat diketahui bahwa diabetes melitus merupakan penyakit kormobiditas terbanyak yang dapat menimbulkan kematian akibat covid-19 di 14 negara (Tahmasebi, Shokri-Kuehni, Sahimi, \& Shokri, 2020). Selain diabetes melitus, penyakit kormobiditas yang lainnya adalah hipertensi (Fang, Karakiulakis, \& Roth, 2020).

Kadar asam urat dalam darah yang meningkat di atas nilai normal dinamakan sebagai hiperurisemia (Andres, J.A. Bernal, \& Pascual, 2017); kadar kolesterol yang meningkat dalam darah dinamakan hiperkolesterolemia sedangkan kadar glukosa yang meningkat dalam darah dinamakan hiperglikemia. Ketiga kondisi ini dapat merupakan bagian dari penyebab penyakit degeneratif atau penyakit tidak menular (PTM) yang berlangsung kronis yang sangat merugikan dan bahkan dapat menimbulkan kematian (Handajani, Roosihermiatie, \& Maryani, 2010). Pada masa pandemi covid-19 dapat diketahui bahwa hipertensi dan diabetes mellitus merupakan penyakit kormobiditas yang juga dapat meningkatkan keretanan untuk lebih mudah terkena covid19 (Fang et al., 2020).

Dengan demikian, pengabdian masyarakat ini perlu dilakukan dengan bertujuan untuk mendeteksi dini adanya hiperurisemia, hiperkolesterolemia dan hiperglikemia sehingga masyarakat dapat menilai kesehatan individu, minimal dari tiga parameter tersebut dan dapat diupayakan pencegahan sejak dini terhadap penyakit degeneratif atau penyakit tidak menular (PTM).

\section{METODE}

Pengabdian masyarakat dilakukan dengan pemeriksaan laboratorium dan penyuluhan. Pihak institusi melakukan perijinan kepada ketua Kelurahan dan Puskesmas Wilayah setempat atas kegiatan tersebut. Pelaksanaan dilakukan di kantor kelurahan Karikil Kota Tasikmalaya pada hari Senin, 13 Januari 2020 pukul 08.00-12.00 WIB. Sasaran penyuluhan adalah masyarakat RW 01 termasuk kader Desa Karikil. Luarahnya adalah berupa gambaran warga yang mengalami hiperurisemia, hiperkolesterolemia dan hiperglikemia. Pelaksanan dimulai dengan tahapan penyuluhan kemudian dilakukan pemeriksaan mengenai kadar asam urat untuk menilai hiperurisemia. Selanjutnya dilakukan pemeriksaan glukosa darah untuk menilai hiperglikemia dan pemeriksaan kolesterol untuk melihat hiperkolesterolemia. Hasil pemeriksaan diperlihatkan kepada salah satu dosen yang sekaligus adalah seorang dokter. Penjelasan mengenai hasil laboratorium dilakukan perorang setelah selesai pemeriksaan. Msayarakat diberitahukan bahwa nilai normal asam urat untuk laki-laki adalah 3,4-7.0 mg/dl, sedangkan untuk perempuan adalah 2,6-5,7 mg/dl. Nilai normal glukosa darah sewaktu yaitu 70-140 mg/dl dan kadar kolesterol normal dalam darah adalah $<200 \mathrm{mg} / \mathrm{dl}$. 


\section{HASIL DAN PEMBAHASAN}

Pengabdian masyarakat dimulai dengan pembukaan acara oleh tim panitia kemudian sambutan dari Ketua Prodi D3 Teknologi Laboratorum Medis STIKes Bakti Tunas Husada Tasikmalaya dan sambutan dari Kepala Kelurahan atau yang mewakili serta Kepala Puskesmas Mangkubumi atau yang mewakili. Selanjutnya dilakukan pemeriksaan darah menggunakan alat digital, yang dapat dilhat pada gambar 1 .

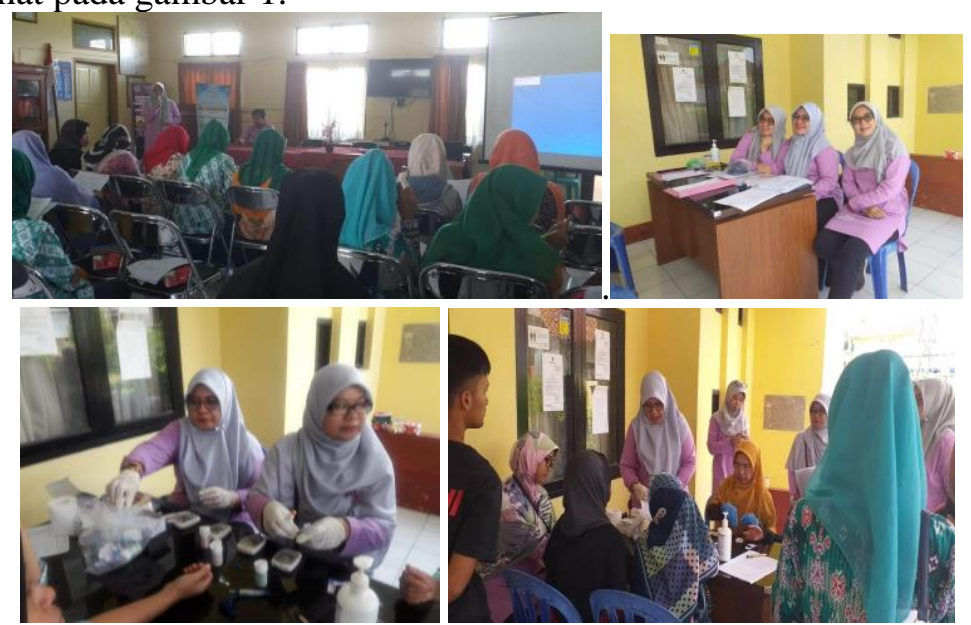

Gambar 1. Sambutan, persiapan, dan pemeriksaan darah

Peserta yang hadir yang mengikuti pemeriksaan darah adalah sebanyak 26 orang. Hasil pemeriksaan darah untuk deteksi dini hiperurisemia, hiperkolesterolemia dan hiperglikemia dapat dilihat pada gambar 2. Hasil pemeriksaan menggambarkan kondisi normal dan juga meningkat. Namun, kondisi yang normal lebih mendominasi dibandingkan dengan yang meningkat atau abnormal.

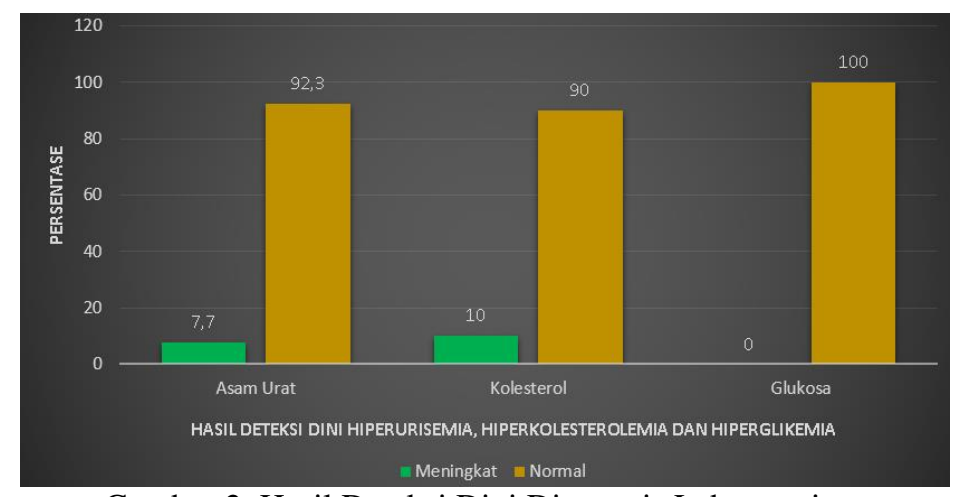

Gambar 2. Hasil Deteksi Dini Diagnosis Laboratorium

Hasil pemeriksaan atau deteksi dini terhadap hiperurisemia, hiperkolesterolemia dan hiperglikemia pada gambar 2, menunjukan hasil yang didominasi oleh keadaan normal secara berurutan 92,3\% (24 orang), $90 \%$ (25 orang), dan $100 \%$ (26 orang), sebagaian kecilnya mengalami hiperurisemia yaitu $7,7 \%$ (2 orang), dan hiperkolesterolemia adalah $10 \%$ (1 orang dari 10 orang yang melakukan pemeriksaan kolesterol).

Pemeriksaan dini tersebut dapat menggambarkan kondisi kesehatan masing-masing individu. Kondisi yang normal harus tetap dipertahankan, sedangkan kondisi yang abnormal atau meningkat perlu ditindaklanjuti agar tidak menimbulkan gangguan kesehatan yang lebih lanjut. Kadar asam urat yang normal untuk perempuan adalah 2,6-5,7 mg/dl, untuk laki-laki 3,4-7,0 mg/dl. Kadar glukosa sewaktu adalah 70-140 mg/dl dan kadar kolesterol yang normal adalah <200 mg/dl. Seperti pada hasil penelitian sebelumnya bahwa kadar hiperurisemia memiliki rata-rata kadar 
cystatin-c 1,08 mg/dl (Meri, 2019; Meri \& Liswanti, 2020) Kadar cystatin ini menggambarkan fungsi ginjal. Jika kadarnya meningkat maka terdapat adanya gangguan fungsi ginjal namun tetap perlu pemeriksaan lanjutan untuk memastikannya. Tidak hanya satu parameter yang dijadikan patokan dalam mendiagnosa. Bagi masyarakat yang mengalami hiperurisemia sebanyak $7,7 \%$ (2 orang) dari total 26 orang, harus bisa menjaga kesehatannya dan berupaya untuk menurunkan kadar asam uratnya, agar terhindar dari penyakit salah satunya penyakit ginjal. Kelebihan asam urat dalam darah akan menimbulkan penumpukan kristal urat pada sendi membentuk monosodium urat (Andres et al., 2017). Kristal inilah yang kemudian akan dikenal oleh inflamasome pada sel imun sehingga menimbulkan peradangan pada bagian sendi (Abbas et al., 2016).

Terdapat $10 \%$ (1 orang) dari 10 orang yang diperiksa mengalami hiperkolesterolemia. Hiperkolesterol dapat menimbulkan arterosklerosis karena adanya kristal kolesterol yang juga dikenali oleh inflamasome pada sel host. Masyarakat yang mengalami hiperkolesterolemia diberikan penjelasan agar mengurangi konsumsi makanan yang mengandung lemak berlebihan. Lemak tersebut dapat berkontribusi dalam resistensi insulin oleh karena produksi interleukin 1 sebagai hasil pengenalan lemak oleh inflamasome terutama dengan kondisi obesitas dengan diabetes melitus tipe 2 (Abbas et al., 2016). Jumlah total pemeriksaan kolesterol ini cukup terbatas dikarenakan keterbatasan dari sisi stock bahan, sehingga jumlah yang diperiksa adalah hanya 10 orang.

Kondisi warga tidak ada yang mengalami hiperglikemia yaitu 100\% (26 orang). Meskipun semua warga tidak mengalami hiperglikemia, namun sebagai warga yang peduli terhadap kesehatan, harus tetap bisa menjaga keseimbangan kesehatan, baik melalui olah raga maupun dengan makan makanan dengan gizi seimbang.

\section{SIMPULAN}

Masyarakat Desa Karikil RW 01 Kecamatan Mangkubumi Kota Tasikmalaya secara berurutan mengalami hiperurisemia, hiperkolesterolemia dan hiperkolesterolemia yaitu sebesar $7,7 \% 10 \%$ dan $0 \%$, sedangkan warga yang normal terhdap kadar asam urat, kolesterol dan glukosa darah adalah $92,3 \%, 90 \%$ dan $100 \%$

\section{SARAN} diperbanyak.

Saran pengabdian masyarakat selanjutnya adalah jumlah sasaran supaya bisa lebih

\section{UCAPAN TERIMA KASIH}

Penulis mengucapkan terima kasih kepada pihak Kepala Kelurahan Karikil Kecamatan Mangkubumi Kota Tasikmalaya dan Kepala Puskesmas Mangkubumi, para kader yang telah berkontribusi dalam kelancaran kegiatan, dan P3M STIkes Bakti Tunas Husada Tasikmalaya yang telah memberikan dukungan financial terhadap kegiatan pengabdian masyarakat ini.

\section{DAFTAR PUSTAKA}

Abbas, A. K., Lichtman, A. h., \& Pillai, S. (2016). Basic Immunology; Functions and Disorders Of The Immune System (Fifth Edit). Canada: Elsevier.

Andres, M., J.A. Bernal, \& Pascual, M. D. A. (2017). Synovial Fluid Leukocyte Count And Its Association With Crystal Deposition In Asymptomatic Hyperuricemia: A Preliminary Report. Scientific Abstracts, 18(June), 2017. https://doi.org/10.1136/annrheumdis-2017-eular.3258

Bishop, M. L., Fody, E. P., \& Schoeff, L. E. (2010). Clinical Chemistry; Techniques, Principles, Correlations (Sixth). Philadelpia: Lippincott Williams \& Wilkins.

Fang, L., Karakiulakis, G., \& Roth, M. (2020). Are patients with hypertension and diabetes mellitus at increased risk for COVID-19 infection?, (January). 
https://doi.org/10.1111/all.14238.Wan

Handajani, A., Roosihermiatie, B., \& Maryani, H. (2010). Faktor-faktor yang berhubungan dengan pola kematian pada penyakit degeneratif di indonesia. Buletin Penelitian Sistem Kesehatan, 13(1), 42-43.

Luo, P., Huang, Y., Xu, T., Ji, Y., Yu, N., \& He, L. (2016). Relationship between hyperuricemia and neutrophil-to-lymphocyte ratio in type 2 diabetes mellitus, 9(10), 10833-10838.

Maiuolo, J., Oppedisano, F., Gratteri, S., Muscoli, C., \& Mollace, V. (2016). Regulation of uric acid metabolism and excretion. International Journal of Cardiology, 213, 8-14. https://doi.org/10.1016/j.ijcard.2015.08.109

Meri, M. (2019). Correlation Between The Absolute Eosinophil Counts With Cystatin C Levels In Hyperuricemia. Biochemical and Cellular Archives, 19(June), 4763-4765. https://doi.org/DOI : 10.35124/bca.2019.19.S2.4763

Meri, M., \& Liswanti, Y. (2020). Hiperurisemia Dan Cystatin C. Jurnal Analis Medika Biosains, $7(1), 14-18$.

Ruilope, L. M., \& Garcia-puig, J. (2001). Hyperuricemia and Renal Function. Cardiovascular Risk and Hypertension, 197-202.

Tahmasebi, P., Shokri-Kuehni, S. M. S., Sahimi, M., \& Shokri, N. (2020). How do environmental, economic and health factors influence regional vulnerability to COVID-19? BMJ, 1-9. https://doi.org/https://doi.org/10.1101/2020.04.09.20059659 